\section{The Botanical Society}

AT a meeting of the Botanical Society held on August 3, 1837, the secretary read a letter from the Botanical Institution of Brussels requesting it might be admitted into friendly correspondence with the Society. Mr. Dennes then read a paper entitled "Observations on the Structure and Germination of the Reproductive Organs of Marsilea". The paper was accompanied by a translation of a memoir on the same subject, made to the Paris Academy of Sciences by MM. Mirbel, Dutrochet and St. Hilaire. In M. quadrifolia (which much resembles cur common trefoil, excepting in its petals being furnished with an additional leaf) there is apparently a longitudinal membranous partition, containing a number of cells each enclosing an hermaphrodite flower. The stamens of these flowers are stated by Jussieu, who was the first to examine the plant minutely, to be so small, and in such numbers, as to render it impossible to count them : they open transversely, to scatter the grains of the spherical yellow pollen. Convincing proofs were adduced from the researches of Dutrochet and St. Hilaire especially, that germination takes place by the impregnation of the ovules with the antheric dust, although this has been strongly opposed by other botanists, who keep all the species of Marsilea in the class Cryptogamia.

\section{The Athenæum and Meteorology}

In its issues of August 5 and 12, 1837, the Athenoum devoted several pages to an essay on meteorology, the subject being suggested by a review of two recently published works. The first of these was by Partick Murphy (1782-1847), and was entitled "Meteorology considered in its Connexion with Astronomy, Climate, and the Geographical Distribution of Animals and Plants". Of the author and this book the Athenoeum said : "We state our firm conviction, that nothing but loss can be the result of his publishing such books as the one before us". Of the other book, Graham Hutchison's "Treatise on the Causes and Principles of Meteorological Phenomena" the reviewer remarked : "This is a sensible, well-executed compilation, interspersed with some new views and explanations of meteorological facts". The subject was one in which the Athenceum took a particular interest and at the beginning of the essay it said: "If there be one branch of science, more than another, which we have endeavoured to place prominently before the public, it has been Meteorology, because it appeared to us of great importance and to have been especially neglected".

\section{The London Electrical Society}

As a result of a resolution passed at a general meeting of the Electrical Society held on August 5, 1837, the Committee issued a report stating that the object for which the Society was formed, as stated in a resolution of May 16, 1837, would be fully carried into effect. The publication of papers had been deferred, as members had intimated their intention of presenting communications, after the recess, containing new facts in electrical science. Among the communications which had already been received was one from Andrew Crosse, of Broomfield, near Taunton, describing some results obtained by him in producing crystals by transferring the electrical energy from the zine and copper plates to other substances not metallic in contact with them.

\section{Societies and Academies}

\section{Paris}

Academy of Sciences, May 31 (C.R., 204, 1597-1692).

Jules Drach : The logical integration of linear differential equations : the reduction of the group. Marcel Delépine and Alann Horeau: The catalysis of the Cannizzaro reaction by active nickel and platinum. The application to some aldoses. The conversion of an aldehyde into alcohol and acid by alkali (Cannizzaro reaction) is greatly accelerated by the addition of a catalyst, Raney nickel or platinum. Results are given for galactose, glucose and arabinose.

Paul VincensinI: The reconstitution of the ensemble of convex bodies of $n$ dimensional space starting from certain base sub-ensembles.

Arnaud DenJoy: A theorem of Mandelbrojt.

Joseph ChaLom : Reaction pumps with supersonic flow.

Assène Datzerf : The solution of Schrödinger's equation.

Jean Lours Destouches: The relativistic wave mechanics of systems and the interaction of light and matter.

Henr Mrneur : Clusters of stars in kinetic equilibrium.

Paul Bourgeors and Jacques Cox : The frequency of the concentrations in extra-galactic nebulæ detected by Hubble's tests.

LUCIEN D'AzAMBUJA : International co-operation for the continuous observation of the sun, and its first results. A summary of results obtained between July 1, 1935, and December 31, 1936. Study of the connexion between chromospheric eruptions and electrical and magnetic disturbances on the earth.

Pierre Vernotte : How to formulate empirical laws. The exponential development.

HenRI Lemonde : The interpretation of variations of viscosity with concentration in binary liquid mix. tures.

RENÉ LUCAS : The thermal waves of liquids.

RenÉ Planiol : The application of molecular jets to the production of light ions.

Jean P. E. Duclaux: The anodic polarization of tungsten. Study of the electrolysis of sulphuric acid with tungsten electrodes. The fall of current with time, due to the formation on the anode of a layer possessing a high resistance, depends on the condition of the surface, and is independent of the current.

Vitomir H. Pavlović : A new method for studying subjectively the mixture of colours.

Maurice Parodi : Study of the transmission of some oxides in the extreme infra-red. Measurements for the oxides of manganese, strontium, cadmium and barium are given. The wave-lengths of the absorption bands plotted against the atomic number fall on a curve resembling a parabola.

Henri Bizette and Belling Tsai : The magnetic rotatory power of compressed and of liquefied nitric oxide, NO. The experimental results suggest that the molecules of nitric oxide commence to polymerize under high pressure at $-80^{\circ} \mathrm{C}$. From the Verdet constant at $-163^{\circ} \mathrm{C}$., it is concluded that 93 per cent of the liquid is in the state of double molecules $(\mathrm{NO})_{2}$, and this agrees with the results of Rice, based on the entropy of vaporization.

P. BONÉT-MAURY: The utilization of photo. elements with semi-conducting layer for radioactive measurements. Selenium or copper photo-cells, 
irradiated with $\alpha$ - or $\beta$-rays, give rise to a difference of potential, exactly as with photons; the $\gamma$-rays have given no appreciable effect. The local variations of sensibility and the effects of fatigue of the element are more marked with $\alpha$-rays than with photons.

Mme. JulietTe GAvORET : The quantitative study of the adsorption of metallic cations by cellulose. The iso-electric point of cellulose.

Mlle. Suzanne Vent : The potential gradient of gelatine under electromotive force.

CASIMIR JaUsseran: The anomalies of the dispersion of light by colloidal solutions of silver. Although the heterogeneity of the medium studied produces special optical properties, its refractive index can be calculated utilizing for the dispersed metal the same optical constants as those of the metal in the massive state.

Mrle. Marie Théodoresco : The study by the Raman effect of two molybdotartaric complex compounds in water. The results are in agreement with those found by the rotatory polarization, namely, the existence of two complex compounds, $\mathrm{Na}_{2}\left(\mathrm{TH}_{2}, \mathrm{MoO}_{3}\right)$ and $\mathrm{Na}_{4}\left(2 \mathrm{TH}_{2}, \mathrm{MoO}_{3}\right)$.

CH. BEDEL : The determination of the solubility of slightly soluble electrolytes, precipitated and in the presence of their reaction products. Application to silver chloride.

Miches Cymboliste: The structure of electrolytic chromium.

Pifrre Mastagli : The reducing and condensing action of alkaline benzylates on ketones and alde. hydes, and on the $\alpha, \beta$ unsaturated alcohols.

Mlles. Marthe Montagne and Marguerite GARRY : The action of organo-magnesium compounds on the phenylimino derivatives of benzil.

ChaRLes BouHeT : The Raman effect in circularly polarized light in quartz, observed along the optic axis.

Louis Dubertret : The constitution and genesis of the green Syrian rocks.

Daniel Barbier, Daniel Chalonge and Etienne VASSY : The variations of temperature of atmospheric ozone according to its origin.

Josú Heilmann Hofret : The genus Trigonoides, a stable genetic mutation of the genus Trigonia.

ANDRé EICHHORN : Chromosome enumeration and the study of mitosis in two Crotolaria.

JEAN TROCHAIN : A new graphical representation of the results of physical and granular analyses of the soil.

Mme. Marguerite Combes : The probable existence of a higher class, not differing in appearance, forming the true workers in the Formica.

Tchou Su and Chen-Chao-Hsi : A new Chinese race of Ascaris megalocephala (type trivalens).

Pierre P. Grassé : Aberrant spermiogenesis of the Metatermitides.

JEHAN VELLARD: Geographical variations of the venom of the South American rattlesnake, Crotalus terrificus.

Henri Brenry : Protein sugar and blood proteins in the normal and pathological states.

V. A. Kostrizin : A generalization of the biological equations in the case of a population intoxicated by the products of its chemical activity.

Jean Lavollay and Mme. Françoise Laborey : The mathematical expression of the development of Aspergillus niger as a function of the concentration of magnesium of the nutritive medium.

Marius Chadefaud: The organization and the trichocytes of Gonyostomum semen.
Henri Simonnet, Gustave Guittonneau, GerMaIN Mocquot and ANDré Exrard: The influence of pasteurization in the absence of air on the nutritive value of milk. The experiments described lead to the conclusion that pasteurization in the absence of air is not incompatible with the preservation of the essential nutritive qualities of milk.

\section{Amsterdam}

Royal Academy (Proc., 40, No. 6, June 1937).

L. S. ORNSTEnN : Scattering of neutrons in matter (5). A discussion of the distribution of the directions of motion of neutrons scattered by protons.

J. A. Schouten: The differential geometry of the groups of contact transformations (3). Infinitesimal doubly homogeneous contact transformations and their applications to mechanics and electrodynamies.

F. M. JAEGER, J. A. BotTema and E. Rosenbohm : Exact measurement of the specific heats of metals at high temperatures (28). The heat capacity and the electrical resistance of didymium between $300^{\circ}$ and $600^{\circ} \mathrm{C}$.

F. M. JAEger and J. TER Berg: On pterotactic derivatives of bivalent platinum with optically active cyclic trans-1.2 diamines.

A. G. van Veen and J. K. BaARs : Constitution of toxoflavin. This substance, produced by the action of Bacterium cocovenenans, is a di-imine containing the purine skeleton and is isomeric with methylxanthine.

O. Posthumus : Some remarks on the vegetation on the sandy soil of the Pandang Loewai (E. Koetai, E. Borneo).

S. W. Visser : A period of twenty-seven months in the rainfall throughout the world.

W. B. Deys and M. J. DrJkman: Splitting off of gallic acid from tannin, especially from theotannin by Aspergillus niger.

M. J. AdrianI : Transpiration of some halophytes cultivated in various media in comparison with that of some non-halophytes.

H. J. Hardon : Padang soil, an example of podsol in the tropical lowlands.

G. C. HIRSCH and R. F. J. vaN PeLt : Rhythm of the glycogen content of the liver of the white mouse.

M. J. L. Dols, B. C. P. JANSEN, G. J. Sizoo and J. DE VRIES : Studies on phosphorus metabolism in normal and rachitic rats with a radioactive phosphorus isotope (see also Nature, June 19, p. 1068).

J. J. DUYVEnÉ DE WIT: Biological evidence of two new hormones by tests on Rhodeus amarus.

\section{Cape Town}

Royal Society of South Africa, May 19.

K. F. M. Bright : The South African inter-tidal zone and its relation to ocean currents. (2) An area on the southern part of the west coast. (3) An area on the northern part of the west coast.

R. F. Lawrence : The odoriferous glands of South African harvest spiders. The external appearance of the odoriferous glands in some South African harvest spiders is described, as well as the colour, volatility, and smell of the secretion of the glands. The activity of the glands is considerably more marked in the large group of Laniatores, some members of which expel the secretion in the form of a fine jet. The ejection of an evil-smelling substance is most probably a defence reflex in this group of Arachnida. 